\title{
Community pharmacists' knowledge of COPD, and practices and perceptions of medication counseling of COPD patients
}

This article was published in the following Dove Press journal: International Journal of COPD

\author{
Juha Markus Heikkilä',2 \\ Stina Parkkamäki \\ Johanna Salimäki ${ }^{4}$ \\ Sari Westermarck ${ }^{5}$ \\ Marika Pohjanoksa-Mäntylä' \\ 'Faculty of Pharmacy, Division of \\ Pharmacology and Pharmacotherapy, \\ University of Helsinki, Helsinki, \\ Finland; ${ }^{2}$ Hartola Pharmacy, Hartola, \\ Finland; ${ }^{3}$ Hyvinkää Willan Kehrä \\ Pharmacy, Hyvinkää, Finland; ${ }^{4}$ The \\ Association of Finnish Pharmacies, \\ Helsinki, Finland; ${ }^{5}$ Tammela \\ Pharmacy, Tammela, Finland
}

Background and purpose: COPD is one of the leading causes of morbidity and mortality worldwide. Although medication counseling interventions by pharmacists have been found to support the management of COPD, little is known about pharmacists' knowledge concerning COPD and regular practices and perceptions concerning medication counseling of COPD patients. The purpose of this study was to research these topics among Finnish community pharmacists.

Materials and methods: In January 2017, an electronic survey was e-mailed to Finnish community pharmacies ( $\mathrm{n}=741$ ) via the Association of the Finnish Pharmacies. One pharmacist from each pharmacy, preferably a specialist in asthma, was invited to answer the survey.

Results: Completed responses were received from 263 pharmacists (response rate $=35 \%$ ), of whom 196 pharmacists were specialists in asthma. Response rate among asthma pharmacists was $42 \%$. Pharmacists were positive about their role in medication counseling and in support of the self-management of COPD patients. COPD-related knowledge was self-assessed as being good and was on a good level in respect of basic facts. However, almost half (46\%) of the pharmacists did not know that COPD is considered a national public health issue, and $\sim 50 \%$ of the pharmacists were not familiar with the current care guideline on COPD. Medication counseling was found to be more medicinal product-driven and less advisory concerning lifestyle changes such as smoking cessation and physical exercise.

Conclusion: Although the pharmacists' knowledge of COPD was good on general topics, there were some gaps in their knowledge on the current care guideline and status of the disease. Pharmacists should more systematically individually target medication counseling according to patients' needs. In addition, lifestyle treatments, including smoking cessation and physical exercise, should be part of the medication counseling.

Keywords: pulmonary disease, medication counseling, pharmacists, clinical practice guideline, knowledge

\section{Introduction}

COPD is one of the leading causes of morbidity and mortality worldwide, and in Western societies, the prevalence of COPD is mostly related to smoking. ${ }^{1}$ However, between 1990 and 2010, the total number of COPD deaths was decreasing globally in all age-groups. ${ }^{2}$ In Finland, the prevalence of COPD is between 3.7\% and 9\%, and COPD is recognized as an important public health issue by the National Institute of Health and Welfare..$^{3-7}$

According to the global strategy for diagnosis, management, and prevention of COPD and several European guidelines, diagnostics of COPD should be improved. ${ }^{1,8-11}$
Correspondence: Juha Markus Heikkilä Faculty of Pharmacy, University of Helsinki, Viikinkaari 5 E, PO Box 56 00014 Finland

Tel +35840021 9232

Email juha.markus.heikkila@gmail.com 
Lifestyle changes such as smoking cessation and physical exercising are important nonpharmacological ways of treating COPD. COPD medicines are used to relieve symptoms, such as dyspnea and to prevent exacerbations. ${ }^{1,8-11}$ Appropriate nutrition and nutrition counseling based on the patient's individual needs should be part of treatment, ${ }^{8,9}$ and influenza and pneumococcal vaccines are recommended for COPD patients. ${ }^{1,8-11}$

The role of pharmacists has been recognized in the treatment of COPD patients, including actions from primary prevention (eg, educational campaigns), through preliminary diagnostics (eg, microspirometry testing), to ongoing support and follow-up of patients and their medications. ${ }^{6}$ Special medication counseling interventions by community pharmacists are found to have a positive impact on patient and treatment outcomes among COPD patients. ${ }^{7-9}$ Two interventions in the Netherlands identified that active medication counseling by community pharmacists was a contributing factor in reducing drug-related problems and improving the quality of life among COPD patients. ${ }^{7,8}$ In addition, acute exacerbations of COPD were found to decrease when comparing preintervention and postintervention data after a year of medication counseling intervention. ${ }^{8}$ Similarly, in the UK, the patients who were assigned a special 10 -week period of medication counseling support from their community pharmacists were found to be more adherent to their COPD medications, to experience better health-related quality of life and to use less general practitioner services compared with the patients who received standard counseling. ${ }^{9}$

In Finland, community pharmacists are obliged by law to administer verbal medication counseling while dispensing medicines to ensure safe and effective pharmacotherapy. ${ }^{16}$ In addition to medication counseling, other health promotion-related professional services, such as special asthma, smoking cessation, and diabetes services, and medication reviews are provided by community pharmacies. ${ }^{17}$ Since 1997, the patients with respiratory diseases have been particularly focused upon by Finnish community pharmacists when pharmacies joined the National Asthma Program. In participating pharmacies, specific asthma pharmacists were named and educated to lead local activities such as education and medication counseling. ${ }^{18}$ In 2017, there were 496 asthma pharmacists in 467 community pharmacies (information from the Association of Finnish Pharmacies). In parallel with the asthma program, a 10-year National Prevention and Treatment Program for Chronic Bronchitis and COPD was started. ${ }^{19}$ The asthma program was continued later by the National Allergy Program and will be continued until
$2018 .{ }^{20}$ As a result of these programs, community pharmacists have expanded their expertise, eg, with smoking cessation services, and pharmacies are increasingly seen as a resource for the prevention and treatment of COPD. ${ }^{19,21}$ During these programs, plenty of research has been conducted on the prevalence of respiratory diseases and smoking, symptoms, hospitalizations, the use of health care services, and costs in Finland. ${ }^{3-6,20-22}$ In addition, some data have been published concerning the asthma-related medication counseling in community pharmacies, and it was considered to have better quality by the asthma pharmacists than by the patients. ${ }^{18}$ However, similar to other countries, little is known about the knowledge, practices, and perceptions related to COPD and its treatment among community pharmacists. The need for research in this area is global as community pharmacists in any country should be competent and knowledgeable about the current care guidelines and should base their medication counseling on evidence-based medicine. Research is needed to identify both existing practices and needs for development, in order to develop COPD medication counseling practices. The purpose of this study was to assess community pharmacists' knowledge of COPD, medication counseling practices, and perceptions within Finnish community pharmacies.

\section{Materials and methods Study design and population}

This was a cross-sectional electronic survey targeting pharmacists working in community pharmacies in Finland in January 2017. One response per pharmacy, representing the practice of the whole pharmacy, preferably from a named asthma pharmacist, who generally is also aware of COPD, was requested. If an asthma pharmacist was not named or not available in a pharmacy, a response from another pharmacist working in medication counseling was asked for.

The first section of the survey was designed to explore pharmacists' self-assessed level of knowledge of COPD and its treatments and measured level of knowledge, by factual questions on COPD and its treatments according to the Finnish current care guideline. ${ }^{8,9}$ The first section included 10 Likert-type statement questions with a choice of four precoded responses (very well, well, poor, and very poor) concerning pharmacists' self-assessed level of COPD knowledge related to reasons, symptoms, progress of the disease, differences and similarities between asthma and COPD, nonpharmacological treatments, inhaled medicinal products, other than inhaled medicinal products, symptoms of exacerbations, treatment of the exacerbations, and knowledge of the current care guideline. We chose a 4-point Likert-type 
scale in order to have specific responses from respondents by making clear choices for them to self-assess their knowledge, counseling practices, and perceptions. In addition, five true/false statements concerning clinical facts of COPD and its treatment were included.

The second section of the survey was designed to explore pharmacists' medication counseling practices of the COPD patients based on the current care guideline ${ }^{8,9}$ and the United States Pharmacopeia (USP) Medication Counseling Behaviour Guideline, ${ }^{23}$ which is shown to be a valid, reliable, and commonly used tool in Finland for evaluating counseling practices. ${ }^{24}$ The USP medication counseling guideline was validated and promoted in community pharmacies in Finland during the medication counseling development project, at the same time as the National Asthma and COPD Programs were running. ${ }^{25}$ In line with the USP guideline, the questions in this section were related to different phases (introduction, main content, and conclusion phases) of the medication counseling session. Eight statement questions in the second part of the survey were concerned with the introduction phase of the medication counseling and covered the following topics regarding the COPD patients and treatment of their disease: smoking status, current symptoms, previous exacerbations, previous medication(s), benefits of previous medication(s), drug-related problems of previous medication(s), physical habits, and nutritional status. Ten statement questions in the second part of the survey were concerned with the main content phase of the medication counseling when COPD medicine was dispensed to the patient, and covered the following topics: advise on smoking cessation and nonsmoking; mode of the action(s) of the medicine(s); dosage(s), regimen(s), schedule(s), and duration(s) of the medicine(s); possible adverse drug reactions; instructions on how to use an inhaler; instructions for possible exacerbation(s); advise on physical exercise; nutritional instructions; recommendation for flu and pneumococcal vaccines; and systematic guidance to seek help from a physician when applicable. One statement question in the second part of the survey was concerned with the conclusion phase of the medication counseling and how the patient was instructed about reliable written information sources regarding COPD and its treatment. The 4-point Likert-type scale with precoded responses (functions very well, functions well, functions poorly, and functions very poorly) was used to answer the second section of the survey.

The last section of the survey explored pharmacists' perceptions of medication counseling of the COPD patients. It contained four Likert-type statements with the choice of four pre-coded responses (Totally agree, Agree, Disagree, Totally
Disagree) concerning pharmacists' perceptions on the following statements: if pharmacists consider the medication counseling work of a COPD patient as meaningful, whether respondents see the role of a pharmacist as important in the chain of different health care professionals, and whether pharmacists see if they can motivate the COPD patient in the treatment of the disease. It was also asked whether the follow-up of COPD patient care in the community pharmacy is possible. In addition, demographic information concerning the pharmacists (gender, year of birth, education level, working years, frequency of COPD medication counseling, and whether asthma pharmacist or not) and the pharmacies (size of the pharmacy, professional special services, and tests offered) was collected.

The face and content validity and technical functionalities of the survey were pilot-tested by a group of specialists including two community pharmacists (BSc and $\mathrm{MSc}$ ), a social pharmacy researcher, a coordinator of the asthma/COPD program from the Association of Finnish Pharmacies, and an adviser from the Helsinki University for survey application. After piloting, some minor changes in the questionnaire were made mainly with wording and some technical issues.

\section{Data collection and analysis}

The survey was e-mailed from the Association of the Finnish Pharmacies to all pharmacies and subsidiary pharmacies. In addition, it was e-mailed to all 17 subsidiary pharmacies of the Helsinki University Pharmacy and to the University Pharmacy of Eastern Finland. Reminders were sent after 1 week and after 2 weeks from the initial e-mail. In total, the survey was sent to 759 e-mail addresses.

Data were quantitatively content-analyzed to compute descriptive statistics by using the Statistical Package for Social Sciences (SPSS for Windows Version 24.0; IBM Corporation, Armonk, NY, USA). The pharmacists' knowledge and medication counseling practices and their associations were analyzed by computing descriptive statistics and bivariate analyses using Pearson's $\chi^{2}$ test for categorical variables when conditions for the test were met. If the conditions for Pearson's $\chi^{2}$ test were not met, the Fisher's exact test was used instead. The Monte Carlo method was applied to the Fisher's exact test with a confidence level of $99 \%$. In the analyses, $p<0.05$ was set as the level of statistical significance.

\section{Ethical consideration}

The study was conducted in accordance with the guidelines of the Finnish National Advisory Board on Research Integrity ${ }^{26}$ and was exempt from review and approval by the Helsinki University's Ethical Review Board, as this was not human 
subject research. The completion of the survey by pharmacists was deemed to be a consent. All the data were collected and analyzed anonymously.

\section{Results}

\section{Participants}

Responses were received from 263 pharmacists (response rate $=35 \%$ ), including 196 asthma pharmacists (response rate $=42 \%$ among asthma pharmacists). The majority of the respondents were female $(92 \%)$, and the answers were received more from bigger pharmacies $(>80,000$ prescriptions dispensed annually) than from small pharmacies (Table 1). Simple medication review, inhalation technique assessment service, and comprehensive medication review were the most commonly provided professional services in community pharmacies where respondents were working (Table 1).

\section{Pharmacists' self-assessed COPD knowledge}

Over $80 \%$ of the respondent pharmacists self-assessed that they knew reasons, symptoms, inhaled medicinal products, and nonpharmacological treatments for COPD very well or well (Table 2). On the other hand, 50\% of the pharmacists considered that they knew the current care guideline and medicinal products, other than inhaled products, poorly or very poorly. Pharmacists counseling COPD patients more often were more likely to assess their knowledge as being better than pharmacists counseling more seldom $(p<0.05)$. In addition, pharmacists working in pharmacies providing professional services and clinical tests (eg, medication reviews, asthma service, diabetes service, COPD assessment tests, and microspirometry) were assessed to have better COPD-related knowledge than pharmacists working in pharmacies without those services $(p<0.05)$. There were no other significant differences in pharmacists' self-assessed COPDrelated knowledge according to pharmacists' and pharmacies' characteristics (eg, age, working years, gender, education, pharmacy size, and asthma vs nonasthma pharmacists).

\section{Pharmacists' measured COPD knowledge}

Respondent pharmacists performed well in the knowledge test with basic true/false statements concerning clinical facts regarding COPD and its treatment. All pharmacists correctly knew the following: 1) smoking is the main reason for COPD and 2) COPD is not curable. Approximately three of four $(73 \%)$ knew that an inhaled corticosteroid is not always
Table I Characteristics of the respondents, study pharmacies, and target population $(n=263)$

\begin{tabular}{|c|c|c|}
\hline Variable & n (\%) & $\begin{array}{l}\text { Target } \\
\text { population } \% \text { a }\end{array}$ \\
\hline \multicolumn{3}{|l|}{ Gender } \\
\hline Female & $242(92)$ & 91.5 \\
\hline Male & $21(8)$ & 8.5 \\
\hline \multicolumn{3}{|l|}{ Year of birth } \\
\hline $1948-1959$ & $26(10)$ & NA \\
\hline $1960-1969$ & $87(33)$ & NA \\
\hline 1970-1979 & $82(3 \mathrm{I})$ & NA \\
\hline 1980-1989 & $55(21)$ & NA \\
\hline $1990-$ & $13(5)$ & NA \\
\hline \multicolumn{3}{|l|}{ Education } \\
\hline BSc (Pharm) & $220(84)$ & 83 \\
\hline MSc (Pharm) & $43(16)$ & 17 \\
\hline \multicolumn{3}{|l|}{ Asthma pharmacist } \\
\hline Yes & $196(75)$ & NA \\
\hline No & $67(25)$ & NA \\
\hline \multicolumn{3}{|l|}{ Working years as a pharmacist } \\
\hline$<10$ & $60(23)$ & NA \\
\hline $10-19$ & $83(32)$ & NA \\
\hline 20-29 & $84(32)$ & NA \\
\hline$>30$ & $36(14)$ & NA \\
\hline \multicolumn{3}{|l|}{$\begin{array}{l}\text { Frequency of COPD medication } \\
\text { counseling }\end{array}$} \\
\hline Less than once a week & $13(5)$ & NA \\
\hline Once a week & $29(11)$ & NA \\
\hline Several times a week, not daily & $86(33)$ & NA \\
\hline Once a day & $69(26)$ & NA \\
\hline Several times daily & $66(25)$ & NA \\
\hline \multicolumn{3}{|l|}{$\begin{array}{l}\text { Size of the pharmacy } \\
\text { (prescriptions per year) }\end{array}$} \\
\hline$<20,000$ & $14(5)$ & 16.5 \\
\hline $20,00 I-40,000$ & $45(17)$ & 24 \\
\hline $40,00 I-60,000$ & $50(19)$ & 14.5 \\
\hline $60,00 \mathrm{I}-80000$ & $33(13)$ & II \\
\hline $80,00 \mathrm{I}-100,000$ & $40(15)$ & 10.5 \\
\hline $100,000-120,000$ & $39(15)$ & 8.5 \\
\hline$|20,00|-\mid 40,000$ & $19(7)$ & 5.5 \\
\hline$>140,000$ & $23(9)$ & 8.5 \\
\hline \multicolumn{3}{|l|}{$\begin{array}{l}\text { Professional services and clinical } \\
\text { tests provided by the pharmacy }\end{array}$} \\
\hline Simple medication review & $139(53)$ & NA \\
\hline $\begin{array}{l}\text { Inhalation technique assessment } \\
\text { service }\end{array}$ & $60(23)$ & NA \\
\hline $\begin{array}{l}\text { Comprehensive medication review } \\
\text { (cross-professional) }\end{array}$ & $52(20)$ & NA \\
\hline PEF measurements performed & $53(20)$ & NA \\
\hline Microspirometries performed & $44(17)$ & NA \\
\hline Asthma service & $37(14)$ & NA \\
\hline Smoking cessation service & $29(11)$ & NA \\
\hline Diabetes service & $2 \mathrm{I}(8)$ & NA \\
\hline Asthma tests performed & $156(59)$ & NA \\
\hline COPD assessment tests performed & $56(2 I)$ & NA \\
\hline
\end{tabular}

Note: anformation received from the Association of Finnish Pharmacies, May 15, 2017.

Abbreviations: NA, information not available; PEF, peak expiratory flow. 
Table 2 Community pharmacists' self-assessed level of knowledge concerning key issues of COPD and the current care guideline in Finland $(n=263)$

\begin{tabular}{|c|c|c|c|c|}
\hline \multirow{2}{*}{$\begin{array}{l}\text { Survey statement } \\
\text { According to self-assessment I know the following key } \\
\text { issues concerning COPD: }\end{array}$} & \multicolumn{4}{|c|}{ Number of responses and percentages to each category } \\
\hline & Very well & Well & Poorly & Very poorly \\
\hline Reasons & $61(23 \%)$ & $178(68 \%)$ & $24(9 \%)$ & $0(0 \%)$ \\
\hline Symptoms & $38(14.5 \%)$ & $200(76 \%)$ & $25(9.5 \%)$ & $0(0 \%)$ \\
\hline Inhaled medicinal products & $34(13 \%)$ & $195(74 \%)$ & $33(12.5 \%)$ & I $(0.5 \%)$ \\
\hline $\begin{array}{l}\text { Nonpharmacological treatments (smoking cessation, } \\
\text { physical exercise, and nutrition) }\end{array}$ & $6 \mathrm{I}(23 \%)$ & $161(61 \%)$ & $41(16 \%)$ & $0(0 \%)$ \\
\hline Similarities and differences between COPD and asthma & $28(10.5 \%)$ & $173(66 \%)$ & $60(23 \%)$ & $2(1 \%)$ \\
\hline Progress of the disease & $26(10 \%)$ & $170(64.5 \%)$ & $66(25 \%)$ & $\mathrm{I}(0.5 \%)$ \\
\hline Symptoms of exacerbations & $21(8 \%)$ & 157 (59.5\%) & $83(31.5 \%)$ & $2(1 \%)$ \\
\hline Treatments of exacerbations & 17 (6.5\%) & |4| (53.5\%) & $104(39.5 \%)$ & I (0.5\%) \\
\hline Non-inhaled medicinal products & $13(5 \%)$ & 115 (43.5\%) & 125 (47.5\%) & $10(4 \%)$ \\
\hline Current care treatment guideline & II (4\%) & $115(44 \%)$ & $134(5 \mid \%)$ & $3(1 \%)$ \\
\hline
\end{tabular}

included in the treatment of the COPD. On the other hand, approximately half $(46 \%)$ of the pharmacists were not familiar that COPD is classified as an important public health issue in Finland. In addition, 44\% of the pharmacists did not know that smoking cessation will stop the progress of the disease. The only significant differences between the groups were related to pharmacists' asthma specialization and provision of comprehensive medication reviews by the pharmacy. Asthma pharmacists had greater knowledge $(p<0.05)$ the role of inhaled corticosteroids in the COPD treatment and the impact of smoking cessation on the progress of the disease, compared with the nonasthma pharmacists. In addition, participants working in pharmacies providing comprehensive medication reviews had greater knowledge $(p<0.05)$ regarding COPD being a national health issue and that a corticosteroid is not always included in the treatment, compared with pharmacists working in pharmacies without this service.

\section{Medication counseling practices} Introduction phase of the medication counseling

Based on pharmacists' self-assessments, the most commonly discussed issue in the introduction phase of the medication counseling was the current symptoms of the patient (Table 3). In addition, approximately half of the pharmacists assessed that they commonly cover, very well or well, previous usage, perceived benefits, and problems of medicines used. However, over $75 \%$ of the pharmacists responded that they usually cover smoking status and physical habits of the COPD patients, poorly or very poorly. More than $90 \%$ of the pharmacists perceived that discussion concerning nutritional status of the COPD patient functions usually, poorly, or very poorly. Pharmacists who counsel COPD patients more often assessed that the clarification of topics related to the patient and usage of earlier medicines in the introduction phase, functions better, compared with those who counsel more seldom $(p<0.05)$. There were significant differences $(p<0.05)$ in some answers according to age and working years: older pharmacists (born earlier than 1969) and pharmacists with $>20$ working years considered that smoking status, nutritional status, and physical activities of the patient were clarified better compared with younger participants with less working experience. Pharmacists working in pharmacies providing asthma service considered that the introduction phase of counseling functions significantly $(p<0.05)$ better, compared with pharmacists working in pharmacies without this service. No other differences between groups were identified.

\section{Main content and conclusion phases of the medication counseling}

The majority of the pharmacists $(>90 \%)$ assessed that in the main content phase of the medication counseling they usually cover well or very well instructions concerning how to use the inhaler and instructions concerning dosage, timing, and maximum dose of the medicine(s) dispensed (Table 3). Other topics pharmacists are likely to cover systematically, well or very well, include instructions to seek the physician's help when applicable ( $80 \%$ of the pharmacists) and counseling for smoking cessation ( $58 \%$ of the pharmacists), whereas the most poorly covered issues include guidance for physical exercise (20\% reported performing well or very well) and nutrition counseling (10\% reported performing very well or well). Concerning the conclusion phase of the medication counseling, $<20 \%$ of the respondents considered that the patient is 
Table 3 Self-assessment of Finnish community pharmacists $(n=263)$ on how medication counseling of COPD patients functions in the introduction, main content, and conclusion phases of the medication counseling session, according to USP Medication Counseling Behaviour Model

\begin{tabular}{|c|c|c|c|c|}
\hline \multirow[t]{2}{*}{ Survey statement } & \multicolumn{4}{|c|}{ Number of responses and percentages for each category } \\
\hline & $\begin{array}{l}\text { Functions } \\
\text { very well }\end{array}$ & $\begin{array}{l}\text { Functions } \\
\text { well }\end{array}$ & $\begin{array}{l}\text { Functions } \\
\text { poorly }\end{array}$ & $\begin{array}{l}\text { Functions } \\
\text { very poorly }\end{array}$ \\
\hline \multicolumn{5}{|l|}{ Introduction phase } \\
\hline Current symptoms & $13(5 \%)$ & 144 (55\%) & $94(35.5 \%)$ & $12(4.5 \%)$ \\
\hline Use of earlier medications & $15(5.5 \%)$ & $136(52 \%)$ & $99(37.5 \%)$ & $13(5 \%)$ \\
\hline Benefits of earlier medications & $14(5.5 \%)$ & $128(48.5 \%)$ & $108(41 \%)$ & $13(5 \%)$ \\
\hline Problems with earlier medications & $9(3.5 \%)$ & $13 \mid(50 \%)$ & $108(41 \%)$ & $15(5.5 \%)$ \\
\hline Possible earlier exacerbations & $6(2.5 \%)$ & $88(33.5 \%)$ & $146(55.5 \%)$ & $23(8.5 \%)$ \\
\hline Current smoking status & $10(4 \%)$ & $5 \mathrm{I}(19 \%)$ & $162(62 \%)$ & 40 (I5\%) \\
\hline Physical status and physical habits & $6(2 \%)$ & $35(13 \%)$ & $159(61 \%)$ & $63(24 \%)$ \\
\hline Nutritional status & $2(1 \%)$ & $18(7 \%)$ & $156(59 \%)$ & $87(33 \%)$ \\
\hline \multicolumn{5}{|l|}{ Main content phase } \\
\hline How to use inhaler & $73(28 \%)$ & $160(61 \%)$ & $24(9 \%)$ & $6(2 \%)$ \\
\hline Dosage, timing, maximum dosage & $47(18 \%)$ & $186(70.5 \%)$ & $25(9.5 \%)$ & $5(2 \%)$ \\
\hline Guidance to seek doctor if applicable & $61(23 \%)$ & $156(59.5 \%)$ & $35(13.5 \%)$ & II (4\%) \\
\hline Adverse drug reactions & $20(8 \%)$ & $140(53 \%)$ & $95(36 \%)$ & $8(3 \%)$ \\
\hline Mode of action & $16(6 \%)$ & $139(53 \%)$ & 90 (34\%) & $18(7 \%)$ \\
\hline Guidance for nonsmoking & $32(12 \%)$ & $122(46.5 \%)$ & 91 (34.5\%) & $18(7 \%)$ \\
\hline Guidance for vaccinations & $30(11 \%)$ & $97(37 \%)$ & $110(42 \%)$ & $26(10 \%)$ \\
\hline Guidance for exacerbation & $9(3.5 \%)$ & $108(4 \mid \%)$ & I 30 (49.5\%) & $16(6 \%)$ \\
\hline Guidance for physical exercise & $5(2 \%)$ & 49 (I8.5\%) & I54 (58.5\%) & $55(21 \%)$ \\
\hline Guidance for nutrition & $3(1 \%)$ & $24(9 \%)$ & $160(61 \%)$ & $76(29 \%)$ \\
\hline \multicolumn{5}{|l|}{ Conclusion phase } \\
\hline Guidance for reliable information sources & $5(2 \%)$ & $46(17.5 \%)$ & $161(61 \%)$ & 51 (19.5\%) \\
\hline
\end{tabular}

Abbreviations: COPD, chronic obstructive pulmonary disease; USP, United States Pharmacopeia.

informed, well or very well, about the information sources of where to find additional information on COPD medicines and care (Table 3). Pharmacists working in pharmacies with professional asthma, diabetes, and comprehensive medication review services were more likely to rate that their medication counseling in the main content and conclusion phases is performed better, compared with pharmacists working in pharmacies without these services $(p<0.05)$. Similarly with the introduction phase, pharmacists who were older (born earlier than 1969) and with a 20-year working history considered that counseling functions significantly $(p<0.05)$ better for smoking cessation, physical exercise and nutrition compared with younger participants with less working experience. No other significant differences were identified in pharmacists' counseling practices in the main content and conclusion phases of the counseling according to pharmacists and pharmacy characteristics (eg, gender, education pharmacy size, and asthma vs nonasthma pharmacists).

\section{Pharmacists perceptions of counseling COPD patients}

The majority of pharmacists (90\%) perceived counseling of COPD patients to be meaningful and agreed (80.5\%) that pharmacists have an important role in the COPD patients' treatment (Table 4). Three of four agreed that as a pharmacist one is able to motivate the COPD patient in the selfmanagement of the disease. The same number of pharmacists (74\%) stated that the follow-up of the patients is possible at a pharmacy level. Respondents working in pharmacies providing comprehensive medication reviews and asthma services perceived their role in COPD treatment more positively $(p<0.005)$ compared with pharmacists from pharmacies without these services. Pharmacists counseling more often stated also $(p<0.05)$ that medication counseling is meaningful, motivating the patient is possible, and the role of a pharmacist was seen as more important, compared with pharmacists who reported counseling COPD patients more seldom. Pharmacists who work in pharmacies where any of the professional services (listed in Table 1) are available agreed significantly more $(p<0.05)$ that motivating the patient is possible, compared with pharmacists from pharmacies without these services. In pharmacies where COPD assessment tests and asthma tests are used, the pharmacists agreed significantly more $(p<0.05)$ that the follow-up of the patients is possible, compared with pharmacies without these tests. There were no differences in the answers according to age, gender, education level, size of the pharmacy, and between asthma and nonasthma pharmacists. 
Table 4 Perceptions of the medication counseling and the role of community pharmacists in the COPD treatment by community pharmacists in Finland $(\mathrm{n}=263)$

\begin{tabular}{|c|c|c|c|c|}
\hline \multirow[t]{2}{*}{ Survey statement } & \multicolumn{4}{|c|}{$\begin{array}{l}\text { Number of responses and percentages to each } \\
\text { category }\end{array}$} \\
\hline & $\begin{array}{l}\text { Totally } \\
\text { agree }\end{array}$ & Agree & Disagree & $\begin{array}{l}\text { Totally } \\
\text { disagree }\end{array}$ \\
\hline Counseling work of COPD patients is meaningful & $120(46 \%)$ & $116(44 \%)$ & $27(10 \%)$ & $0(0 \%)$ \\
\hline Pharmacist has an important role in the treatment chain of COPD patients & $80(30.5 \%)$ & $134(5 \mid \%)$ & $44(16.5 \%)$ & $5(2 \%)$ \\
\hline Pharmacist can motivate COPD patients for the self-management of the disease & $54(20.5 \%)$ & $|4|(53.5 \%)$ & $64(24.5 \%)$ & $4(1.5 \%)$ \\
\hline As a pharmacist, follow-up of COPD patients is possible & $49(18.5 \%)$ & I 44 (55\%) & $61(23 \%)$ & $9(3.5 \%)$ \\
\hline
\end{tabular}

\section{Discussion}

Although recent reports suggested that pharmacies are recognized as important providers of support for COPD patients, ${ }^{12}$ the present study is, according to our understanding, the first study concerning community pharmacists' knowledge, practices, and perceptions of medication counseling of COPD patients. While community pharmacists' involvement may be beneficial for patients, ${ }^{13-15}$ it is important that pharmacists are familiar with, and base their counseling on, evidence-based current care guidelines. The present study demonstrated that Finnish community pharmacists perceive themselves as important providers of medication counseling and support for the COPD patients' treatment. Although most pharmacists self-assessed to have good knowledge on COPD, some gaps were identified in both medication counseling practices and pharmacists' knowledge. Similarly with previous studies conducted in other European countries, especially the level of knowledge about the current care guideline was found to be suboptimal. Continuing education is needed not only on the content of the current care guidelines, but also on how to apply those guidelines into evidence-based medication counseling in practice.

This study identified that Finnish pharmacists are familiar with reasons and the progress of COPD and with the fact that inhaled corticosteroids are not always included in the treatment of COPD. On the other hand, only slightly over half of the pharmacists knew that COPD is considered as a national health issue, which is in line with the awareness of the current care guideline, which was, according to selfassessment, known well or very well by $48 \%$ of the participants. This finding is consistent also with previous research on the familiarity of the current care guideline on smoking cessation among community pharmacists in Finland: 47\% of the respondents were familiar with the guideline 4 years after its' original publication and 1 year after its update in 2007. ${ }^{27}$ Similarly, a study from England found that the local current care guideline or COPD management was read by approximately $47 \%$ of community pharmacists. ${ }^{28}$
According to the survey, medication counseling in pharmacies is more medicinal product driven rather than based on the individual status and needs of each COPD patient. This is reflected in the finding that, while counseling COPD patients, pharmacists more commonly discuss previous use of medicines than, eg, smoking status and other lifestyle issues (eg, nutrition and physical activity) of the patient. In addition, the focus on actual medication counseling is on correct, safe, and effective use of medicines and in the correct use of inhalers. This fulfills the requirements of Finnish legislation that requires the community pharmacist to ensure safe and effective pharmacotherapy. ${ }^{16}$ Topics concerning other selfmanagement of COPD, such as advice on smoking cessation, physical exercise, and nutrition, seem not to be the major topics in medication counseling even though these are important treatment methods of COPD according to global and local guidelines. ${ }^{1,8-11}$ This finding is in line with previous findings from community pharmacies from Belgium and the Netherlands where medicinal product-related topics such as dosage, inhalation technique, and adverse drug reactions are discussed more often when counseling COPD patients, while, eg, guidance for smoking cessation and physical exercise are included less often in medication counseling. ${ }^{29,30}$ The same finding was also seen in a different therapeutic area; medication counseling concerning antidepressants by community pharmacists was more medicinal product driven rather than related to, eg, lifestyle changes of the patients. ${ }^{31}$

Different professional services offered in pharmacies seem to have a positive effect on counseling practices. Especially asthma service and a comprehensive medication review seem to have an impact on more active counseling. This finding is in accordance with the Norwegian study demonstrating that pharmacists' participation in the medication review processes improves the quality of medication management skills. ${ }^{32}$ In Finland, the comprehensive medication reviews are provided by pharmacists with special training. ${ }^{33}$ Education for comprehensive medication review includes topics for clinical interview, which might lead to 
a more individual approach in medication counseling work. The expertise and communication skills of these specially educated pharmacists may be imparted to and adopted by other employees in pharmacies where medication reviews are provided, which might be seen in the results of this study. The survey showed also, interestingly, that older pharmacists with more working years self-assessed to perform lifestylerelated (advise smoking cessation, physical exercise guidance, and nutritional guidance) counseling work better than younger colleagues in both the introduction phase and the main content phase of the counseling.

\section{Practice implications and future studies}

In the strategy for rational use of medicines by the Finnish Medicines Agency, one strategic goal is that health care professionals utilize reliable medicines information sources and base their medication counseling on evidence-based current care guidelines. ${ }^{34}$ From this point of view, wider awareness of the COPD current care guideline and its better implementation to medication counseling in community pharmacies should be further developed. This is supported by the Finnish study where it was shown that pharmacists who knew the current care guideline on smoking cessation better, used its information more widely for the benefit of the patients. ${ }^{27}$ This study showed that medication counseling is medicinal product driven, and it should be developed to be more tailored and holistic and based on each patient's individual needs. To reach this goal, a nationwide development project has already been started for medication counseling in community pharmacists led by cooperative groups of different organizations (oral information from the Association of Finnish Pharmacies). The project is a continuation of earlier projects for developing medication counseling ${ }^{35}$ and implementing medication review as a professional service in community pharmacies in Finland. ${ }^{36}$ The study also indicated that professional services might have a positive impact on counseling practices and pharmacists' COPD knowledge. This might be due to the special education and knowledge needed for these professional services. However, continuing education is still needed to confirm that pharmacists have the competency and skills to take a more holistic approach to counseling COPD patients in practice and to be more aware of current care guidelines. The education should include aspects concerning the importance of smoking cessation, physical exercise, and medication counseling in relation to each patient's individual status and individual needs so that pharmacists are able to communicate and manage these issues with COPD patients.
For the purposes of developing pharmacy education on COPD and COPD counseling, further quantitative and qualitative studies may be complemented from both the pharmacists and patients' perspectives. More information is needed about patient perceptions of their information needs of COPD that should be taken into account while counseling patients in pharmacies. This would be highly important in order to better support self-management of the patients by community pharmacists. In addition, the survey used in this study, based on USP's medication counseling model and modified according to the local current care guideline, could be studied to evaluate its comprehensiveness, especially from the COPD patients' perspectives, and to evaluate the content validity of the survey. Longitudinal studies are required to explore how COPD counseling practices change over time and to assess the implementation of the recent development project on medication counseling, especially from the perspective of this patient group. In addition, the effect and costeffectiveness of medication counseling of COPD patients need further investigation. Longitudinal studies concerning practices of medication counseling could also be made with a pseudo customer method to increase the objectivity. Pseudo customers have been used in Finland earlier also in connection with studies concerning medication counseling practices in community pharmacies. ${ }^{37}$ Furthermore, the finding of this study, concerning older pharmacists with more working years being more active in counseling regarding lifestyle-related topics (eg, smoking, physical activity, and nutritional status) of COPD patients, could be further studied, eg, by a pseudo customer method to assess whether it is a real phenomenon or only self-perception by older pharmacists.

\section{Strengths and limitations}

To our knowledge, this is the first specific study concerning the knowledge of COPD, medication counseling practices, and perceptions concerning medication counseling of COPD patients among community pharmacists. The survey was sent to all Finnish community pharmacies, and thus, the result represents the nationwide situation. In addition, in terms of gender, educational level, age, and working years, the pharmacists who responded to this survey represent very well the general pharmacist population in Finland. However, respondents were not likely to have been representatives of all Finnish pharmacists. It is possible that the perspective of pharmacists working in smaller pharmacies were not fully captured.

On the other hand, the survey was preferentially given to pharmacists who were asthma specialists; among these 
pharmacists, the response rate was $42 \%$. Therefore, the answers represent more the nationwide views of asthma pharmacists than the general pharmacist population in Finland. The face and content validity of the survey instrument was examined among experts including general pharmacists; however, it may have benefited by also including some asthma pharmacists. The response rates in recent studies in Finnish community pharmacies (sent by e-mail) have yielded response rates between $45 \%$ and 55\%. ${ }^{38,39}$ The response rate among asthma pharmacists in this study is about the same.

Due to the use of a Likert-type scale in the survey, the data have been analyzed by using bivariate analysis. This may increase the type I error risk, which should be recognized when interpreting the results relating to the associations between variables. However, descriptive statistics and bivariate tests provided a valid and reliable overview of the key study questions: pharmacists' self-assessed knowledge of COPD, medication counseling practices, and perceptions of counseling of COPD patients. Further studies are needed in order to provide more comprehensive understanding of demographic and other factors associated with pharmacist knowledge, practices, and perceptions of counseling COPD patients.

\section{Conclusion}

Our study showed that community pharmacists perceived that they have an important role in counseling COPD patients and supporting their self-management of the disease. Pharmacists self-assessed that they have good knowledge about COPD and its treatment, and this was also evident concerning the basic facts of COPD and its treatment. However, some gaps were identified in the pharmacists' knowledge on the current care guideline and in the status of COPD as a national public health issue. COPD medication counseling was found to be medicinal product driven in all phases of the medication counseling, and important lifestyle changes such as smoking cessation and physical exercise as nonpharmacological treatments of COPD are not actively screened or counseled. Medication counseling is not very individual according to a patient's status and needs. Continuing education is needed to implement the evidence-based current care guideline better in the medication counseling practice and to promote a more holistic and individual approach in counseling COPD patients in community pharmacies.

\section{Acknowledgment}

The authors gratefully acknowledge all the participants in the survey.

\section{Author contributions}

All the authors have substantial contributions to conception and design and acquisition, analysis, and interpretation of data. JH has been a key person in analyzing the data and drafting the manuscript. All other authors have participated in preparation by critically revising and finalizing the manuscript, gave final approval of the version to be published and agree to be accountable for all aspects of the work.

\section{Disclosure}

The authors report no conflicts of interest in this work.

\section{References}

1. Global Initiative for Chronic Obstructive Lung Disease (GOLD). From the global strategy for the diagnosis, management and prevention of COPD. 2016. Available from: http://goldcopd.org/. Accessed September 10, 2017.

2. Burney P, Patel J, Newson R, Minelli C, Naghavi M. Global and regional trends in COPD mortality, 1990-2010. Eur Respir J. 2015;45: 1239-1247.

3. Kainu A, Rouhos A, Sovijärvi A, Lindqvist A, Sarna S, Lundbäck B. COPD in Helsinki, Finland: socioeconomic status based on occupation has an important impact on prevalence. Scand J Public Health. 2013; 41:570-580.

4. Vasankari TM, Impivaara O, Heliövaara M, et al. No increase in the prevalence of COPD in two decades. Eur Respir J. 2010;36:766-773.

5. Kanervisto M, Vasankari T, Laitinen T, Heliövaara M, Jousilahti P, Saarelainen S. Low socioeconomic status is associated with chronic obstructive airway diseases. Respir Med. 2011;105:1140-1146.

6. Kainu A, Pallasaho P, Pietinalho A. No change in prevalence of symptoms of COPD between 1996 and 2006 in Finnish adults - a report from the FinEsS Helsinki Study. Eur Clin Respir J. 2016;3:31780.

7. National Institute for Health and Welfare, Chronic Diseases, general information, 2014. Available from: https://thl.fi/en/web/chronic-diseases/ general-information-about-chronic-diseases-affecting-public-health . Acccessed September 10, 2017.

8. Working Group appointed by the Finnish Medical Society Duodecim and the Finnish Respiratory Society. Current care guideline of chronic obstructive pulmonary disease (COPD). 2014. Available from: http://www.kaypahoito.fi/web/kh/suositukset/suositus?id=hoi06040. Accessed September 10, 2017.

9. Kankaanranta H, Harju T, Kilpeläinen M, et al. Diagnosis and pharmacotherapy of stable chronic obstructive pulmonary disease: the Finnish guidelines. Basic Clin Pharmacol Toxicol. 2015;116:291-307.

10. National Institute for Health and Care Excellence. Quality standard: chronic obstructive pulmonary disease in adults. 2016. Available from: https://www.nice.org.uk/guidance/qs10. Accessed September 10, 2017.

11. Miravittles M, Vogelmeier C, Roche N, et al. A review of national guidelines for management of COPD in Europe. Eur Respir J. 2016;47: 625-637.

12. van der Molen T, van Boven J, Mguire T, Goyal P, Altman P. Optimizing identification and management of COPD patients - reviewing the role of the community pharmacist. Br J Clin Pharmacol. 2017;83:192-201.

13. Ottenbros $\mathrm{S}$, Teichert M, de Groot R, et al. Pharmacist-led intervention study to improve drug therapy in asthma and COPD patients. Int J Clin Pharmacol. 2014;36:336-344.

14. van Boven J, Stuurman-Bieze A, Hiddink EG, Postma MJ. Effects of targeting disease and medication management interventions towards patients with COPD. Curr Med Res Opin. 2016;32:229-239.

15. Wright D, Twigg M, Barton G, Thornley T, Kerr C. An evaluation of a multi-site community pharmacy-based chronic pulmonary disease service. Int J Pharm Pract. 2015;23:36-43. 
16. Medicines Act 398/1987, Ministry of Social Affairs and Health. 2017. Available from: http://www.finlex.fi/fi/laki/ajantasa/1987/19870395. Accessed September 10, 2017.

17. Bell JS, Väänänen M, Ovaskainen H, Närhi U, Airaksinen M. Providing patient care in community pharmacies: practise and research in Finland. Ann Pharmacother. 2007;41:1039-1046.

18. Mononen A, Niskanen A, Nummi S, et al. Apteekkien astmaohjelman seurantatutkimukset [Implementation of the National Asthma Programme in Finnish Community Pharmacies]. Dosis. 2010;27:100-113. Finnish.

19. Pietinalho A, Kinnula VL, Sovijärvi AR, et al. Chronic bronchitis and chronic obstructive pulmonary disease. The Finnish Action Programme, interim report. Respir Med. 2007;101:1419-1425.

20. Haahtela T, von Hertzen L, Mäkelä M, Hannuksela M; Allergy Programme Working Group. Finnish Allergy Programme 2008-2018 - time to act and change the course. Allergy. 2008;63:634-645.

21. Kinnula V, Vasankari T, Kontula E, Sovijärvi A, Säynäjakangas O, Pietinalho A. The 10-year COPD Programme in Finland: effects on quality of diagnosis, smoking, prevalence, hospital admissions and mortality. Prim Care Respir J. 2011;20:178-183.

22. Kauppi P, Peura S, Salimäki J, Järvenpää S, Linna M, Haahtela T. Reduced severity and improved control of self-reported asthma in Finland during 2001-2010. Asia Pac Allergy. 2014;5:32-39.

23. Airaksinen M, Pohjanoksa-Mäntylä M, Puumalainen I. Theoretical basis and context of the patient counselling services by pharmacists, counselling, in the booklet concordance, communication, innovation education for pharmacists by International Pharmaceutical Federation (FIP) and IPFS. 2012. Available from: https://fip.org/files/fip/HaMIS/ fip_ipsf_pce_2nd_2012.pdf. Accessed September 10, 2017.

24. Puumalainen I, Halonen P, Enlund H, Johnson K, Airaksinen M. Validation of the United States Pharmacopeia (USP) medication counseling behavior guidelines. Pharm Educ. 2005;5:87-96.

25. Puumalainen I, Kansanaho H, Varunki M, Ahonen R, Airaksinen M. Usefulness of the USP Medication Counselling Behavior Guideline. Pharm World Sci. 2005;27:465-468.

26. Finnish Advisory Board on Research Integrity. Responsible conduct of research and procedures for handling allegations of misconduct in Finland. 2012. Available from: http://www.tenk.fi/sites/tenk.fi/files/ HTK_ohje_2012.pdf. Accessed September 10, 2017.

27. Kurko T, Linden K, Pietilä K, Sandström P, Airaksinen M. Community pharmacists' involvement in smoking cessation: familiarity and implementation of national smoking cessation guideline in Finland. BMC Public Health. 2010;10:444.
28. Verma A, Harrison A, Torun P, Vestbo J, Edwards R, Thorton J. Are pharmacists reducing COPD's impact through smoking cessation and assessing inhaled steroid use? Respir Med. 2012;106:230-234.

29. Tommelein E, Tollenaere K, Mehuys E, Boussery K. Pharmaceutical care for patients with COPD in Belgium and views on protocol implementations. Int J Clin Pharm. 2014;36:697-701.

30. Driesenaar JA, De Smet PA, van Hulten R, Hu L, van Dulmen S. Communication during counseling sessions about inhaled corticosteroids at the community pharmacy. Patient Prefer Adherence. 2016;10: 2239-2254.

31. Chong WW, Aslani P, Chen TF. Pharmacist-patient communication on use of antidepressants: a simulated patient study in community pharmacy. Res Social Adm Pharm. 2014;10:419-437.

32. Bell HT, Granas AG, Enmarker L, Omli R, Steinsbekk A. Nurses' and pharmacists' learning experiences from participating in interprofessional medication reviews for elderly in primary health care - a qualitative study. BMC Fam Pract. 2017;18:30.

33. Jyrkkä A, Kaitala S, Aarnio H, Airaksinen M, Toivo T. Kliininen haastattelu osana lääkehoitojen arviointeja ja omahoidon tukemista [Clinical interview as part of medication reviews and support for medication self-management]. Dosis. 2017;33:22-33. Finnish.

34. Finnish Medicines Agency, Fimea. Rational use of medicines through information and guidance, medicines information services: current state and strategy for 2020. Fimea develops, assesses and informs serial publication 1/2012. Available from: http://www.fimea.fi/ documents/160140/1153780/20853_Fimea_KAI_JULKAISUSARJA_ Laakeinformaatiostrategia_1_2012_lopullinen_verkkoon.pdf/4c2e20b702a9-46e6-83ca-eebc55d2ad8c. Accessed September 10, 2017.

35. Kansanaho H, Puumalainen I, Varunki M, Ahonen R, Airaksinen M. Implementation of a professional program in Finnish community pharmacies in 2000-2002. Patient Educ Couns. 2005;57:272-279.

36. Leikola S, Tuomainen L, Peura S, et al. Comprehensive medication review: development of a collaborative procedure. Int J Clin Pharm. 2012;34:510-514.

37. Puumalainen II, Peura SH, Kansanaho HM, Benrimoj CSI, Airaksinen MSA. Progress in patient counseling practices in Finnish community pharmacies. Int J Pharm Pract. 2005;13:149-156.

38. Sinnemäki J, Saastamoinen LK, Hannula S, Peura S, Airaksinen M. Starting an automated dose dispensing service provided by community pharmacies in Finland. Int J Clin Pharm. 2014;36:345-351.

39. Westerling A, Hynninen J, Haikala V, Airaksinen M. Opinion comparison concerning future information technology in Finnish community pharmacies. Pharm World Sci. 2010;32:787-794.
International Journal of COPD

\section{Publish your work in this journal}

The International Journal of COPD is an international, peer-reviewed journal of therapeutics and pharmacology focusing on concise rapid reporting of clinical studies and reviews in COPD. Special focus is given to the pathophysiological processes underlying the disease, intervention programs, patient focused education, and self management protocols.

\section{Dovepress}

This journal is indexed on PubMed Central, MedLine and CAS. The manuscript management system is completely online and includes a very quick and fair peer-review system, which is all easy to use. Visit $\mathrm{http}: / / \mathrm{www}$. dovepress.com/testimonials.php to read real quotes from published authors. 